NASA Technical Memorandum 106925

AIAA-94-3311

\title{
Discharge Ignition Behavior of the Space Station Plasma Contactor
}

Timothy R. Sarver-Verhey

NYMA, Inc.

Engineering Services Division

Brook Park, Ohio

and

John A. Hamley

National Aeronautics and Space Administration

Lewis Research Center

Cleveland, Ohio

Prepared for the

30th Joint Propulsion Conference

cosponsored by AIAA, ASME, SAE, and ASEE

Indianapolis, Indiana, June 27-29, 1994

National Aeronautics and

Space Administration 


\title{
Discharge Ignition Behavior of the Space Station Plasma Contactor
}

\author{
Timothy R. Sarver-Verhey* \\ NYMA, Inc. \\ NASA Lewis Research Group \\ Brook Park, $\mathrm{OH}$ \\ and \\ John A. Hamley ${ }^{\dagger}$ \\ NASA Lewis Research Center \\ Cleveland, $\mathrm{OH}$
}

\begin{abstract}
Ignition testing of hollow cathode assemblies being developed for the Space Station plasma contactor system has been initiated to validate reliable multiple restart capability. An ignition approach was implemented that was derived from an earlier arcjet program that successfully demonstrated over 11,600 ignitions. For this, a test profile was developed to allow accelerated cyclic testing at expected operating conditions. To date, one hollow cathode assembly has been used to demonstratee multiple ignitions. A prototype hollow cathode assembly has achieved 3615 successful ignitions at a nominal anode voltage of $18.0 \mathrm{~V}$. During the ignition testing, several parameters were investigated, of which the heater power and pre-heat time were the only parameters found to significantly impact ignition rate.
\end{abstract}

\section{Introduction}

A plasma contactor has been selected for use on the International Space Station Alpha to alleviate the deleterious effects of structural charging. ${ }^{1}$ Controlled charged particle emission via an ionized gas discharge can couple the station structure to the ambient space plasma $^{2,3}$ and prevent high voltage arcing that may result in the loss of the structural anodized coating due to sputtering as well as arcing damage to insulating surfaces on the station. ${ }^{4}$ The plasma contactor selected is a hollow cathode-based device derived from the ion propulsion and plasma contactor development programs at NASA Lewis Research Center (LeRC). A program was initiated in 1992 to define the operation and performance of a hollow cathode-based plasma contacting device that will meet the required mission life of two years. ${ }^{4}$ As part of this program, componentlevel testing of the plasma contactor system (PCS) is underway $5,6,7$ to validate life time capabilities and performance. Reliable ignition capability of a hollow cathode device is an element that requires validation over the projected life of the PCS.

Development and understanding of a reliable cathode ignition procedure has been the subject of several studies relating to electric propulsion applications. Electrostatic ion thrusters have used hollow cathodes for many years, operating first with mercury propellant, then with the inert gases of argon, xenon, and krypton. Successful ignition with mercury propellant has been demonstrated in ground- and space-based tests. $8,9,10,11,12$ The typical ignition procedure that was developed for mercury propellants consisted of the following steps:

i. Apply heater power to cathode and cathode vaporizer for a fixed period necessary to reach their respective temperatures.

ii. Apply a high DC voltage (several hundred to several thousand volts) between cathode and anode electrodes.

iii. Wait for discharge breakdown to occur.

With the success of this approach using mercury propellant, this procedure was used when the transition was made to inert gas propellant though the vaporizer was no longer needed. This ignition approach has been demonstrated by Beattie et al., ${ }^{13}$ Kitamura et al., ${ }^{14}$ Shimada et al., ${ }^{15}$ and Cirri et al., ${ }^{16}$ where ion thruster main and neutralizer hollow cathodes have been successfully ignited up to several thousand times.

The successful igntion approach described required a keeper supply with a high voltage section which repesents a mass and parts count penalty. Additionally, the duration of the waiting period at high DC voltage until ignition were unpredictable. Alternative ignition approaches have sought to reduce the power processor impacts and allow for more predictable ignition times. These efforts have included heaterless ignition, which has been demonstrated by Schatz ${ }^{17}$ for thousands of successful ignitions. However, heaterless ignition was possible only with a high voltage DC power supply providing several hundred to several thousands volts

\footnotetext{
* Plasma Test Engineer

$\dagger$ Electrical Engineer
}

This paper is a work of the U.S. Government and is not subject to copyright in the United States. 
and by 'pulsing' the gas flow to momentarily raise the local gas pressure to levels that will enhance discharge breakdown. As a result, while the heater was eliminated from the system, other modifications made to accommodate the ignition requirements added back to the system complexity.

For the PCS, an approach has been selected which was derived from the results of Sarmiento and Gruber. ${ }^{18}$ Their approach used an integral pulse generator winding on the output filter inductor of the power processor for a $1 \mathrm{~kW}$ class hydrogen/nitrogen arcjet. This circuit provided a series of brief high voltage pulses which broke down the propellant gas, leading to discharge ignition. This approach was used to successfully demonstrate 11,600 ignition cycles in a hydrogen/nitrogen arcjet.

This pulse generator circuit has been incorporated into the output filter of the anode power supply of the PCS hollow cathode assembly (HCA). This approach offers two advantages over previous ignition approaches. First, the high voltage DC power supply required for the ignition breakdown voltage has been eliminated. The pulse generator circuit provided the necessary voltage for breakdown, then operated as a pass-through device during discharge operation. Second, the ignition pulse ensured an immediate and reliable discharge initiation without the required waiting periods of up to several minutes at high DC voltage that have traditionally been required. Secondary benefits of ignition on demand were better indications of declining PCS performance and mitigated expellant requirements due to elimination of gas flows associated with high DC voltage waiting periods.

At this time, the total number of ignitions required for the PCS has not been fully defined, due to the impact of other concerns such as expellant requirements on operation. There are two operating scenarios that define the limits of ignition requirements. First, the operating profile may require extinction and ignition of the HCA with every orbit. This requirement would necessitate a minimum number of approximately 11,700 ignitions for the projected two year life of the PCS. To date, no hollow cathode or hollow cathode-based device has demonstrated this capability. Second, under continuous operation of the PCS for two years, the ignition requirements fall substantially. For this case, it has been estimated that nominally up to 150 ignitions could be experienced onorbit. Consequently, successful demonstration of a minimum of 1500 ignitions would provide a high degree of confidence in an ignition approach to be safely applied to the second case. Since it is not known at this time whether ignition on every orbit will be required, extended duration tests in excess of 1500 ignition cycles are anticipated

This test program was initiated to validate the PCS HCA ignition capability and behavior via accelerated cyclic ignition tests. A test operation profile was developed to allow accelerated testing of the HCAs under operating conditions that are functionally identical to on-station conditions. A dedicated vacuum facility has been established for this test program. Unattended operation was facilitated by a computerbased data acquisition system which controls and records the ignition testing. To date, a single $\mathrm{HCA}$ has been tested for multiple ignition cycles. This HCA was a prototype device which was used to develop and validate the operational capability of the testing facility. Additionally, the test profile parameters were examined using this HCA. This paper will report on the results of the ignition testing performed to date.

\section{Experiment Apparatus}

\section{Hollow Cathode Assembly}

The HCA consisted of a hollow cathode which was a refractory metal tube with a thoriated tungsten orifice plate welded to one end. A porous tungsten insert impregnated with a $\mathrm{Ba}-\mathrm{Ca}-\mathrm{Al}$ oxide compound to lower the work function was placed inside the tube at the end with the restrictor plate. A helical wound heater was placed over the exterior of the tube at the location of the insert. This configuration was similar to previous hollow cathode wear tests that have been performed at NASA LeRC. 4,5,19,20 The cathode tube was mounted in an insulator to maintain electrical isolation from the anode. The anode was a refractory metal cylinder with a restrictor plate welded at the downstream end which enclosed the cathode and heater. The restrictor plate orifice was centered on the cathode orifice. The anode was attached to the insulator to maintain both the relative position on centerline and the relative distance between cathode and anode orifice plates as well as electrically isolated the anode from the cathode. The HCA is shown schematically in Fig. 1.

The upstream end of the cathode tube was connected to an in-line insulator that electrically isolated the cathode from the feed-system. Upstream of the insulator, the device was connected to the expellant feed-system.

The prototype HCA used for this testing was developed early in this program and was fabricated with demountable mechanical connections to allow repeated assembly and disassembly. In addition, no inline isolator was used to provide electrical and thermal isolation during operation.

\section{Xenon Expellant Feed System}

The expellant gas feed-system was similar to those used in prior cathode tests. ${ }^{3-6}$ The feed-line was 0.64 $\mathrm{cm}$ diameter stainless-steel electro-polished tubing. All fittings used ultra high vacuum metal gasket seals. The internal pressure of the feed-line was maintained at 239 $\mathrm{kPa}(20$ psig) in the feed-line segment upstream of the flow control valve. Flow rate was manually regulated 
with a micrometer valve. An electro-pneumatic shutoff valve was installed downstream of the micrometer valve to start and stop the xenon flow at the beginning and end of each test cycle.

\section{Expellant}

Research grade xenon (99.999\%) gas was used throughout the ignition test. The xenon delivery pressure was maintained at $239 \mathrm{kPa} \pm 7 \mathrm{kPa}$ (20 psig \pm 1 psig).

\section{Power Supplies}

Two power supplies were used to operate the HCAs as shown in Fig. 2. A $16 \mathrm{~V}, 10 \mathrm{~A}$ current-regulated supply provided the required power for the cathode heater during activation and starting. A $55 \mathrm{~V}, 6 \mathrm{~A}$ current-regulated power supply provided the necessary voltage for maintenance of the discharge. The ignition pulse generator circuit was placed in series with the anode power supply. The HCA was isolated from facility ground while the anode was connected to the positive output of the discharge supply and electrically isolated from the test port.

\section{Ignition Circuit}

The ignition circuit used in this work was taken directly from the output circuit of the anode power supply of the breadboard power electronics unit currently under development. This circuit, first described by Sarmiento and Gruber, ${ }^{18}$ utilized the output filter inductor of the power supply as a pulse transformer. This circuit reliably generated high voltage pulse trains with pulse amplitudes ranging from hundreds of volts to several kilovolts. A schematic diagram of the circuit is shown in Fig. 3. Discharge ignition was accomplished by allowing the anode power supply to develop full open circuit voltage. If anode current was not detected, transistor Q1 was turned on, charging the magnetizing inductance of the pulse transformer primary. With a constant excitation voltage, the ignition circuit current, $\mathrm{I}_{\mathrm{p}}$, waveform was a ramp with constant slope described by

$$
d I_{p}=\frac{V_{e} d t}{L_{m}}
$$

where $\mathrm{V}_{\mathrm{e}}$ is the excitation voltage, $\mathrm{L}_{\mathrm{m}}$ is the magnetizing inductance of the pulse transformer primary, and dt is the ON time for Q1. The pulse was generated when Q1 was turned off, and the rapid negative $\mathrm{dI}_{\mathrm{p}} / \mathrm{dt}$ reverses the voltage polarity of the transformer primary. The length of time required for the primary current to return to zero was largely determined by the value of capacitor $\mathrm{C} 1$, which sets the pulse duration. This duration can be approximated by

$$
t=2 \pi(L m C 1)^{1 / 2}
$$

The pulse appeared on the output of the power supply, with its amplitude increased by the turns ratio of the pulse transformer, or

$$
V_{s}=\frac{V_{p} N_{s}}{N_{p}}
$$

where $\mathrm{V}_{\mathrm{S}}$ was the secondary pulse amplitude, $\mathrm{V}_{\mathrm{p}}$ was the primary pulse amplitude, and $\mathrm{N}_{\mathrm{s}} / \mathrm{N}_{\mathrm{p}}$ was the turns ratio of the transformer. The total pulse energy can be described by

$$
J=\frac{1}{2} L m I_{p}^{2}
$$

where $I_{p}$ was the instantaneous primary current at Q1 turn off. The circuit had a further advantage in that the discharge current, $\mathrm{I}_{\mathrm{S}}$, at breakdown was inherently limited to the primary current at the instant of breakdown multiplied by the inverse of the transformer turns ratio, or

$$
I_{s}=\frac{I_{p} N_{p}}{N_{s}}
$$

Pulse amplitude and duration were continuously variable. Increases in amplitude were facilitated by increasing the $\mathrm{ON}$ time of Q1. Changing $\mathrm{C} 1$ varied the pulse duration.

This circuit was used primarily in conjunction with commercial power supplies for operation of the HCA. Alternatively, stand alone testing of the circuit was accomplished by replacing the anode power supply of Fig. 3 with a simple short circuit. The start circuit was then connected directly to the HCA cathode and anode for observation of breakdown characteristics. The necessary condition for successful ignition was that the discharge voltage after breakdown be less than the open circuit voltage of the power supply the ignition circuit will be used with. Simulation of the anode power electronics was accomplished with the $55 \mathrm{~V}, 6 \mathrm{~A}$ current-regulated power supply described above, set to a maximum voltage output of $30 \mathrm{~V}$. The secondary of the pulse transformer was placed in series with the positive output of the power supply, and the open circuit voltage of the commercial supply was set to match the open circuit voltage of the anode power electronics. The pulse circuit was disabled automatically if the discharge current exceeded $1.0 \mathrm{~A}$.

\section{Data Acquisition and Control System}

The power systems and data acquisition system were controlled by a computer. The heater and anode discharge supplies were controlled via a common interface bus and the ignitor circuit was controlled by a digital-to-analog converter. All parameters were 
measured every $6 \mathrm{~ms}$. The collected data were displayed in real-time during the test and recorded to the hard disk at intervals of 1 minutes for the discharge stage, and 2 minutes for the pre-heating and cooling stages. Calibration of the recorded data was performed prior to the ignition tests.

\section{Instrumentation}

The parameters monitored during testing were the anode voltage and current, as well as the AC components on each, xenon mass flow rate, cathode temperature, and test port pressure.

Signal conditioning circuit panels were installed in series with the electrical leads between the power supply and HCA. Measurements of anode current were made via current transducers on these panels. Both heater and anode voltages were measured at the test flange of the vacuum facility.

The HCA temperature measurements were made with a disappearing filament optical pyrometer which sighted on the cathode orifice plate from the opposite side of the vacuum facility, as shown in test configuration schematic in Fig. 4.

For pressure measurements, a Bayard-Alpert ion gauge monitored the facility pressure. The xenon flow rate was measured with a thermal-capacitance mass flow meter. All parameters listed above, except for discharge AC components and cathode temperatures, were recorded at regular intervals to a computer.

\section{Vacuum Facility}

The ignition tests were performed in a cryogenicallypumped bell jar with a xenon pumping capacity of $2100 \mathrm{~L} / \mathrm{sec}$. The hollow cathode was mounted in a 0.3 $\mathrm{m}$ diameter test port attached to the bell jar. A $0.3 \mathrm{~m}$ pneumatic gate valve provided isolation of the bell jar during equipment changes. The test port and bell jar are shown in the photograph in Fig. 5. The facility had a base pressure of approximately $4.0 \times 10^{-5} \mathrm{~Pa}$ and an operating pressure of $6.4 \times 10^{-2} \mathrm{~Pa}$ at normal test conditions.

\section{Test Approach}

Validation of the ignition approach developed for the PCS HCA required several extended cyclic tests of multiple devices. These cyclic tests were required to be operated over ranges that replicated the on-station conditions for the PCS. In order to demonstrate ignition capability with several devices, an accelerated test profile was developed that enabled cyclic operation of the HCA over the expected conditions. The HCA was installed in the vacuum facility (Fig. 4) and ignited and operated at a steady-state emission current between cathode and the anode. No external anodes were used for ignition testing. The multiple tests to be used to validate ignition performance are summarized in Table
I. Testing completed at the time of publication included the first test of the prototype $\mathrm{HCA}$ that was used to prepare the ignition test facility and to examine the cyclic profile parameters.

\section{Test Procedures}

\section{Mass Flowmeter Calibration}

The mass flow meter was calibrated before and after the test on xenon with a bubble flow calibrator.

\section{Feed System Evaluation}

The contamination level within the expellant feed system was characterized by pressure-rise testing. Pressure-rise tests consisted of evacuating the feed system to below $10^{-2} \mathrm{~Pa}$, then isolating the feed-line from vacuum and monitoring the rise in pressure over time with a capacitance manometer mounted in the feed system. This pressure rise was attributed to leakage through the fittings and outgassing from the internal surfaces.

\section{Feed System Bake-out}

Before initiation of the wear-test as well as after each change-out of the xenon bottle, the expellant feed system was baked out to facilitate outgassing of water vapor trapped on the interior tubing surfaces. Heat tape was wrapped over the feed-line and powered to raise the tubing temperature. The bake-out lasted approximately 24 hours. The heat tape was then turned off, and the feed system was allowed to cool before continuing to cathode activation.

\section{Cathode Activation Procedure}

The cathode activation procedure used in this test program was derived from an activation procedure developed during the Solar Electric Propulsion Subsystem program ${ }^{21}$ and which has been subsequently modified for use with the HCA. The same activation procedure was performed after each discharge shutdown where the HCA was exposed to atmosphere.

\section{Ignition Test Cycle}

The ignition test cycle profile was developed to ensure that a HCA was operated over the full thermal envelope expected at the nominal orbital conditions. However, rather than operate the cycle for the expected orbital time of approximately 90 minutes, the discharge $\mathrm{ON}$ and $\mathrm{OFF}$ times were minimized. This accelerated test cycle consisted of:

i. Pre-heat the cathode at a heater current setting of 7.2 $\mathrm{A} \pm 0.05 \mathrm{~A}$ for five minutes.

ii. Open electro-pneumatic valve to start xenon flow, and turn on the anode power supply.

iii. Discharge initiated either by application of opencircuit voltage of anode power supply or by 
subsequent ignition pulse. If no ignition occurs, cycle continues to end.

iv. Maintain the discharge at an emission current of $2.0 \mathrm{~A} \pm 0.05$ for five minutes.

v. Shut off the anode power supply and xenon flow and allow HCA to cool for 10 minutes.

vi. Repeat cycle.

An example of the ignition test cycle is shown in Fig. 6 , where the cycle is defined by the behavior of heater voltage and current, discharge voltage and current, and xenon flow rate. The discharge ON and OFF times were minimized to the times necessary for the HCA to undergo maximum temperature changes.

\section{Ignition Pulse Application}

The ignitor was triggered a few seconds after the 5 minute pre-heat. Immediately after the pre-heat, the shut-off valve on the xenon feed-line was opened and gas started flowing at the run condition setpoint. At the same time, the anode power supply was turned on at the pre-set maximum voltage of $30.0 \mathrm{~V} \pm 0.5 \mathrm{~V}$. The delay between xenon flow and ignition pulse was necessary to prevent disruptive interaction with the ion gauge in the facility. After this delay, the ignitor circuit was commanded on at a pulse frequency of $10 \mathrm{~Hz}$. The ignitor circuit was activated for up to 20 seconds, after which the ignitor was turned off and the cycle would continue. If the discharge started within 20 seconds, the pulsing would cease when the emission current exceeding $1.0 \mathrm{~A}$, and the ignition test cycle would continue.

\section{Parametric Characterization}

The first test in the ignition test plan was designed to assist in the set-up of the test facility by providing a test article for evaluation and calibration of the data acquisition and control systems and test profile development. As part of this work, the prototype HCA was tested under variation of the following parameters to determine effect on ignition rate: discharge ON time, discharge OFF time, expellant start delay, and cathode pre-heat times. The results of these tests will be incorporated into the test profile to be used with subsequent engineering model HCA tests.

\section{Results and Discussion}

\section{Ignition Pulse Behavior}

The ignition pulse output is shown in Fig. 7 under two conditions. First, Fig. 7(a) shows the pulse output with the circuit configured for a stand alone test. In the configuration, the HCA was at ambient temperature with no xenon flow. The set point of the ignitor output at the beginning of all ignition tests was approximately $660 \mathrm{~V}$, which is shown in this figure. The pulse was again measured during a HCA ignition, as shown in
Fig. 7(b), at the start of a test cycle. In this configuration, the circuit was attached to the anode power supply, and the HCA was operated with applied heater power and xenon flow at run condition. The ignitor output reached approximately $65 \mathrm{~V}$ within 0.28 $\mu \mathrm{s}$, for a rate-of-rise of $230 \mathrm{~V} / \mu \mathrm{s}$, before the discharge broke down. At breakdown, the discharge current rose a peak of approximately $5.9 \mathrm{~A}$ for approximately 0.26 $\mu$ s before decreasing to $2.0 \mathrm{~A}$ steady-state. The ignitor circuit was disabled by the increased current flow and pulsing stopped. There were no indications that the ignitor pulse changed over the course of the ignition testing.

\section{Prototype Hollow Cathode Assembly Ignition Tests}

The prototype HCA has achieved a total of 3615 ignitions during evaluation testing. Of these 3615 ignitions, 3375 were performed sequentially. The cyclic ignition testing was performed in several segments due to data acquisition system and facility problems. A test chronology is provided in Table II. The nominal time for ignition breakdown was approximately 3.72 seconds from the start of the ignitor pulsing, which corresponds to an average of 37 pulses until breakdown. The performance of the HCA is shown in Fig. 8, where the anode voltage is shown as a function of cycle number. The anode voltages were measured during the last minute of discharge operation. The anode voltage started at $12.8 \mathrm{~V}$ and rose to $18.0 \mathrm{~V}$ by cycle 1438 . After that, the anode voltage maintained the nominal value of $18.0 \mathrm{~V} \pm 0.3 \mathrm{~V}$. The cause for the increasing anode voltage between cycle 388 and 1563 is not known at this time. However, there are two factors which may have contributed to this voltage increase. First, the HCA experienced severe off-normal steady-state operation during the shutdown at cycle 387. The shutdown was caused when the main isolation valve (see Fig. 4) closed unexpectedly. After this valve closed, the HCA continued to operate at a steady-state emission current of $2.0 \mathrm{~A}$ and the applied heater power of 7.2 A for about 11 hours, during which the local xenon pressure increased to approximately $27 \mathrm{~Pa}$. After the test was stopped and all systems were recovered, cyclic ignition testing was resumed with no immediate changes in operation. Second, the HCA had been used for approximately 100 hours under a variety of conditions prior to use in this test. Both of these factors contributed to aging of the insert, which may have manifested as the monotonic increase of anode voltage to the nominal value of $18.0 \mathrm{~V}$. However, there are insufficient data available at this time to conclusively determine the cause of the voltage increase.

The AC components of anode voltage and current were measured periodically and found to have nominal peak-to-peak values of $1.6 \%$ and $0.38 \%$ of the measured parameters. These values were the levels measured at the end of the discharge cycle, when the 
discharge had stabilized. Measurements early in the discharge stage found much larger levels for the nominal peak-to-peak values of $9.6 \%$ and $6.5 \%$ for voltage and current, respectively.

The erratic, cycle-to-cycle behavior in the anode voltage is attributed to the daily variations in xenon flow due to ambient temperature changes and flow rate set point drift. Note that the anode voltage did not exceed the required maximum value of $22 \mathrm{~V}$ during the 3598 discharge cycles. The xenon flow rate was stable throughout the ignition testing at a nominal value of $8.07 \pm 0.14 \mathrm{~Pa}-\mathrm{L} / \mathrm{s}(4.78 \pm 0.08 \mathrm{sccm})$.

\section{Prototype Hollow Cathode Assembly Parameter Characterization}

Over the course of ignition testing, the sensitivity of the HCA to several operating parameters were investigated. First, the heater current was initially set to $6.65 \mathrm{~A}$ rather than the $7.2 \mathrm{~A}$ target setpoint because pre-test performance testing was successful at that current setting. However, over the course of the first 338 ignition cycles, the ignition rate achieved was better than $73.1 \%$, or 247 ignitions. The pre-heat current setpoint was increased to $7.2 \mathrm{~A}$ at this point, and the ignition rate increased to $100 \%$. All subsequent ignitions were performed at a pre-heat current setpoint of $7.2 \mathrm{~A}$

Second, the discharge ON time and the discharge OFF time were increased to address the effect of HCA thermal equilibrium on ignition. First, the discharge ON time was increased from 5 minutes to 30 minutes for 200 cycles. This change did not effect the ignition rate. Second, the discharge OFF time was increased to 30 minutes for 110 cycles. The discharge $\mathrm{ON}$ time was returned to 5 minutes during these cycles. Again, no changes in ignition rate or operating performance were observed.

Next, the time delay between initiation of xenon flow and application of both anode supply open-circuit voltage and ignitor voltage was increased from 4 to 15 seconds to insure that increased local pressure effects were not effecting ignition performance. This delay was maintained for 665 cycles, during which the ignition rate was $100 \%$.

Finally, the cathode pre-heat time was shortened from 5 minutes to as low as 3.0 minutes. The ignition rate maintained $100 \%$ at pre-heat times as low as 3.5 minutes. However, at 3.0 minutes, the ignition rate dropped to zero. The $100 \%$ ignition rate was regained once the pre-heat time was increased to 4.0 minutes.

The results of the parameter characterization indicated that the HCA ignition capability was sensitive to applied heater power and the time of heater power application. All other parameters examined did not significantly effect ignition rate or $\mathrm{HCA}$ performance. These results suggest that the HCA must reach a minimum temperature before ignition can occur. Other effects, such as cathode insert surface condition, may affect ignition, but were not separately discernible from the results of the parameter characterization

\section{Conclusions}

Ignition testing of a hollow cathode assembly being developed for the Space Station plasma contactor system to verify multiple restart capability has begun in a dedicated vacuum facility. An ignition approach was implemented that was derived from a power processor developed for an arcjet program that successfully demonstrated over 11,600 ignitions. For this test program, a test profile was developed to allow accelerated cyclic testing at projected operating conditions. To date, one hollow cathode assembly has successfully demonstrated multiple ignitions at conditions similar to those expected on-orbit. This prototype HCA has achieved 3615 successful ignitions. Nominal operating conditions were $18.0 \mathrm{~V}$ and 8.07 $\mathrm{Pa}-\mathrm{L} / \mathrm{s}$ for anode voltage and xenon flow rate, respectively. The anode voltage rose from an initial value of $12.8 \mathrm{~V}$. During the ignition testing, several parameters were investigated, of which the heater power and pre-heat time were the only parameters found to significantly impact ignition rate. Further ignition testing will be performed in the near future to validate the ignition capabilities of enginnering model hollow cathode assemblies.

\section{Acknowledgments}

The authors would like to acknowledge the technical support of R. Buttler, G. Jacynycz, R. Jocko, B. Loyer, D. Metcalf, J. E. Parkes, M. Pastel, J. Poboda, and J. Zakany in the preparation and execution of the ignition testing.

\section{References}

1 Moorehead, R.W., Deputy Director, Space Station Freedom Program and Operations, communication to Work Packages 1-4 Directors, dated April 3, 1992.

2 Olsen, R.C. and Whipple, E.C., "Active Experiments in Modifying Spacecraft Potential: Results from ATS-5 and ATS-6," NAS 5-23481 Final Report, May 1977.

3 McPherson, D.A., Cauffman, D.P., and Scheber, W.R., "Spacecraft Charging at High Altitudes: SCATHA Satellite Program," Journal of Spacecraft and Rockets, Vol. 30, No. 3, May-June 1993, pp. 258290. 
4 Patterson, M.J., Hamley, J.A., Sarmiento, C.J., Manzella, D.H., Sarver-Verhey, T.R., Soulas, G.C., and Nelson, A., "Plasma Contactor Development for Space Station," NASA TM 106425, Sept. 1993.

5 Sarver-Verhey, T.R., "Continuing Life Test of a Xenon Hollow Cathode for a Space Plasma Contactor," AIAA Paper 94-3312, June 1994.

6 Soulas, G.C., "Hollow Cathode Heater Development for the Space Station Plasma Contactor," NASA CR 191131, Sept. 1993.

7 Patterson, M.J., Hamley J.A., Sarver-Verhey, T.R., and Soulas, G.C., "Functional Testing of the Space Station Plasma Contactor," AIAA Paper 94-3308, June 1994.

8 Wintucky, E.G., "High Voltage Pulse Ignition of Mercury Discharge Hollow Cathodes," NASA TM X71425, Oct.-Nov. 1973.

${ }^{9}$ Dulgeroff, C.R., Beattie, J.R., Poeschel, R.L., and Hyman, J., "IAPS (8-cm) Ion Thruster Cyclic Endurance Test," IEPC Paper 84-37, 1984.

10 Francisco, D.R., Low, C.A., and Power, J.L., "Successful Completion of a Cyclic Ground Test of a Mercury Ion Auxiliary Propulsion System," NASA TM 101351 , Oct. 1988.

${ }^{11}$ Kerslake, W.R. and Finke, R.C., "SERT II Hollow Cathode Multiple Restarts in Space," AIAA Paper 731136, Oct.-Nov. 1973.

12 Kitamura, S., Nagano, H., Nakamura, Y., Kudo, I., and Machida, K., "ETS-III Ion Engine Flight Operations in the Extended Mission Period," Journal of Propulsion and Power, Vol. 2, No. 6, Nov.-Dec. 1986.

13 Beattie, J.R., Matossian, J.N., and Robson, R.R., "Status of Xenon Ion Propulsion Technology," AIAA Paper 87-1003, May 1987.

${ }^{14}$ Kiramura, S., Miyazaki, K., and Hayakawa, Y., "Cyclic Test of a $14 \mathrm{~cm}$ Diameter Ring-Cusp Xenon Ion Thruster," AIAA Paper 92-3146, July 1992.

15 Shimada, S., Satoh, K., Gotoh, Y., Nishida, E., Noro, T., Takegahara, H., Nakamaru, K., and Nagano, H., "Ion Thruster Endurance Test Using Development Model Thruster for ETS-VI," IEPC Paper 93-169, Sept. 1993.
16 Cirri, G.F., Cipriani, A., Matticari, G., Severi, A., Bartoli, C., Saccoccia, G., and Von Rohden, H., "Review of Qualification Activities on the Neutralizer for the RIT 10 Ion Thruster," IEPC Paper 93-109, Sept. 1993.

17 Schatz, M.F., "Heaterless Ignition of Inert Gas Ion Thruster Hollow Cathodes," NASA TM 87086, Sept.Oct. 1985.

18 Sarmiento, C. J. and Gruber, R.P., "Low Power Arcjet Thruster Pulse Ignition," NASA TM 100123, June-July 1987.

19 Sarver-Verhey, T.R., "Extended-Testing of Xenon Ion Thruster Hollow Cathodes," NASA CR 189227, July 1992.

20 Soulas, G.C., "Multiple Hollow Cathode Wear Testing for the Space Station Plasma Contactor," AIAA Paper 94-3310, June 1994.

21 DePauw, J.F., "30 cm Thruster Cathode Activation,” NASA TRIM No. 13, Dec. 1977. 
Table I. PCS Hollow Cathode Assembly Ignition Test Plan

\begin{tabular}{|c|c|c|c|}
\hline HCA Test Article & Purpose of Test & $\begin{array}{c}\text { Number of } \\
\text { Ignition Cycles }\end{array}$ & Status of Test \\
\hline Prototype & $\begin{array}{l}\text { Demonstration of } \\
\text { Accelerated } \\
\text { Ignition Cycling }\end{array}$ & 3598 & Completed \\
\hline $\begin{array}{l}\text { Engineering Model } \\
\text { (EM) }\end{array}$ & $\begin{array}{c}\text { Verification of } \\
\text { Ignition Capability }\end{array}$ & 1500 & In progress \\
\hline $\mathrm{EM}$ & $\begin{array}{c}\text { Verification of } \\
\text { Ignition Capability } \\
\text { and Unit-to-Unit } \\
\text { Repeatability }\end{array}$ & 1500 & To be performed \\
\hline EM & $\begin{array}{l}\text { Verification of } \\
\text { Ignition Capability } \\
\text { and Unit-to-Unit } \\
\text { Repeatability }\end{array}$ & 1500 & To be performed \\
\hline $\mathrm{EM}$ & $\begin{array}{c}\text { Verification of } \\
\text { Extended Ignition } \\
\text { Capability } \\
\end{array}$ & $9000+$ & To be performed \\
\hline
\end{tabular}

Table II. Prototype Hollow Cathode Assembly Ignition Test Chronology

\begin{tabular}{cccc}
\hline $\begin{array}{c}\text { Test Segment } \\
\text { No. }\end{array}$ & No. of Cycles & $\begin{array}{c}\text { Parameters Investigated } \\
\text { During Segment }\end{array}$ & $\begin{array}{c}\text { Ignition Frequency } \\
(\%)\end{array}$ \\
\hline 1 & 247 & Heater current $=6.65 \mathrm{~A}$ & 73.1 \\
\hline 2 & 141 & $\begin{array}{c}\text { Heater current increased to } \\
7.2 \mathrm{~A}\end{array}$ & 100 \\
\hline 3 & 1177 & $\begin{array}{c}\text { Discharge OFF time } \\
\text { increased, Discharge ON } \\
\text { time increased }\end{array}$ & 100 \\
\hline 4 & 812 & Pre-heat time decreased & $>3.5$ min. -100 \\
& 1224 & Standard profile & 100 \\
\hline 5 & &
\end{tabular}




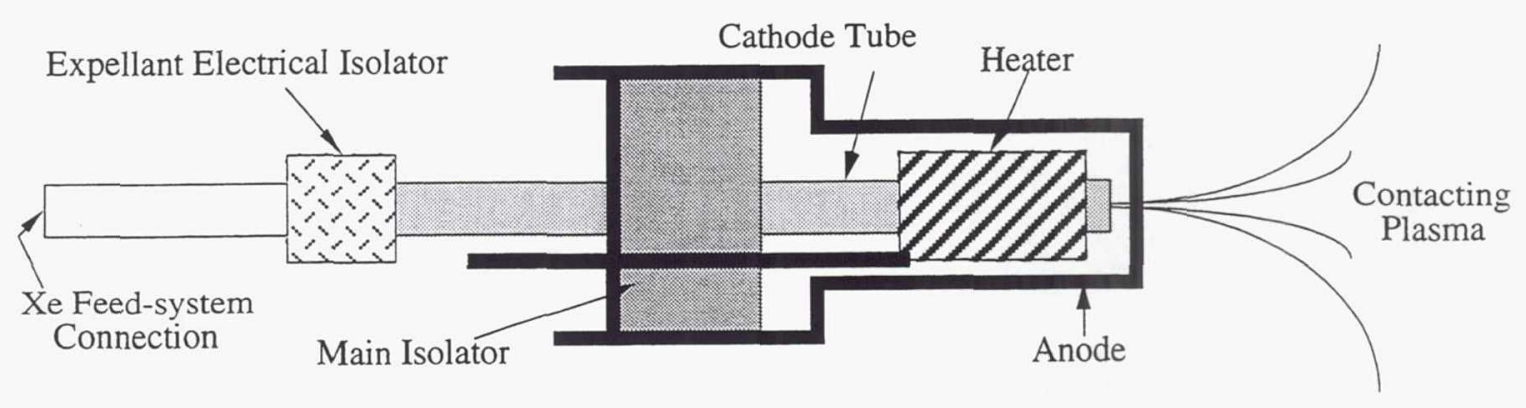

Fig. 1 Schematic of hollow cathode assembly.

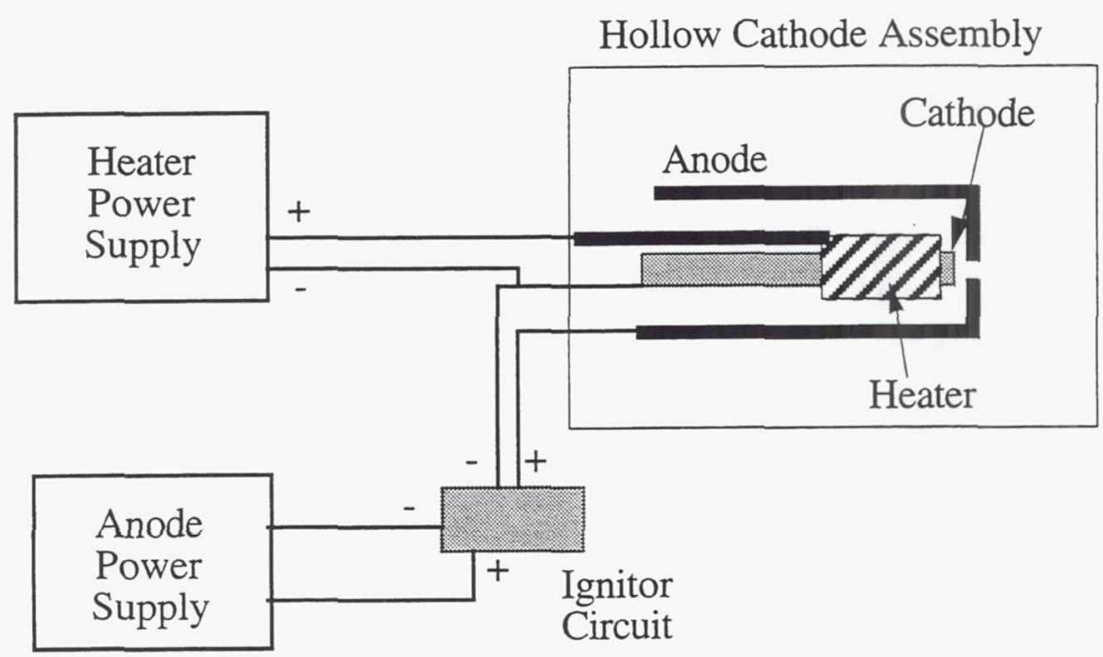

Fig. 2 Schematic of HCA electrical circuit. 


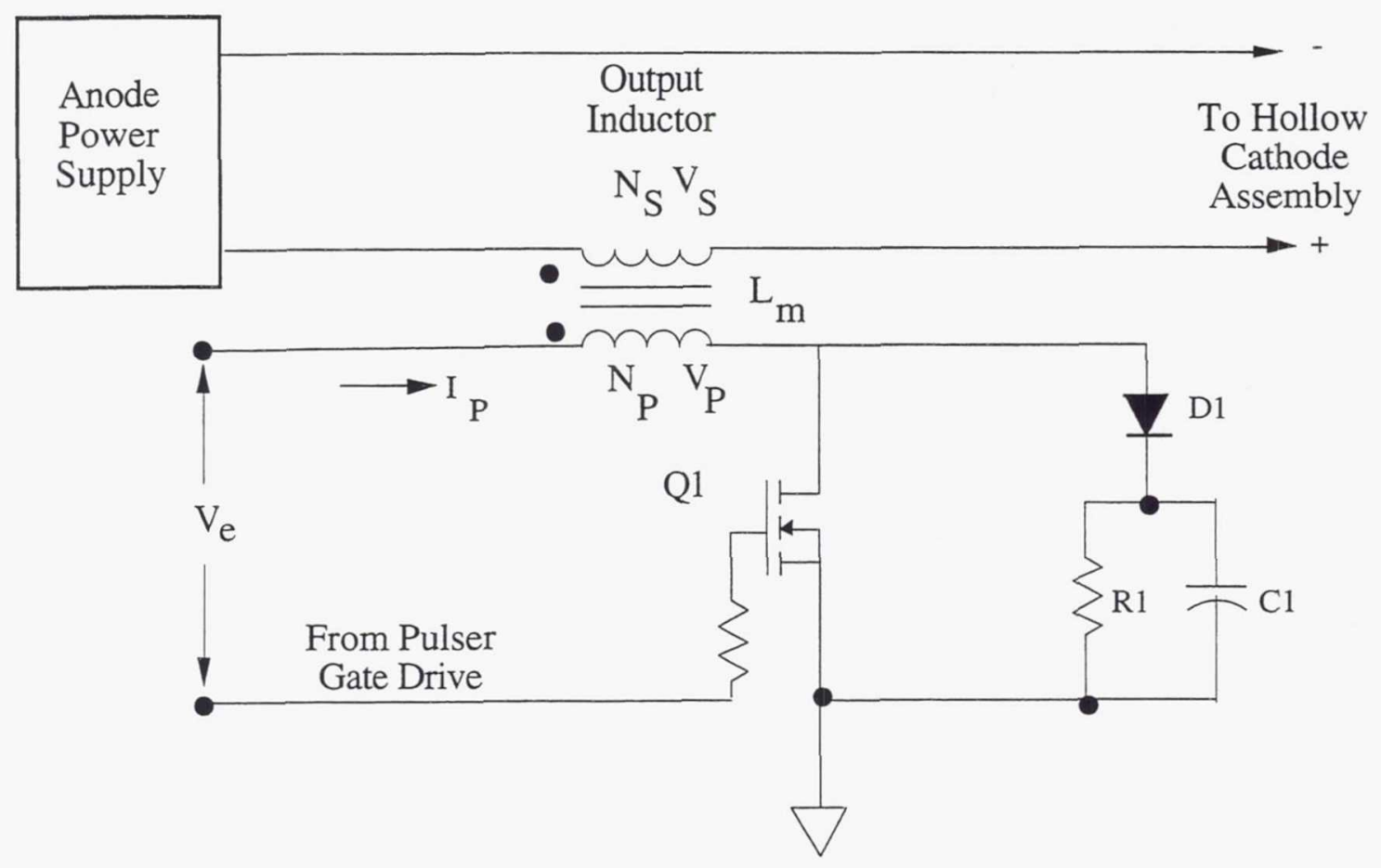

Fig. 3 Schematic of HCA ignition circuit.

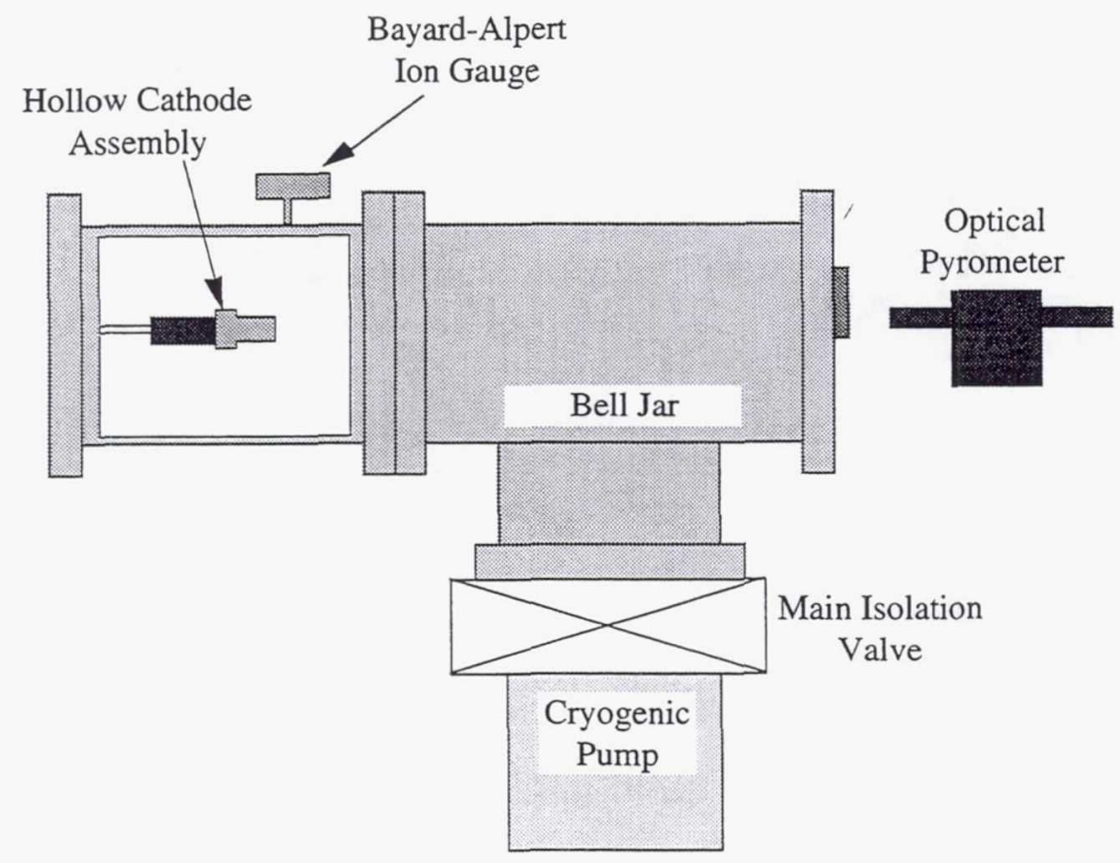

Fig. 4 Ignition test configuration. 


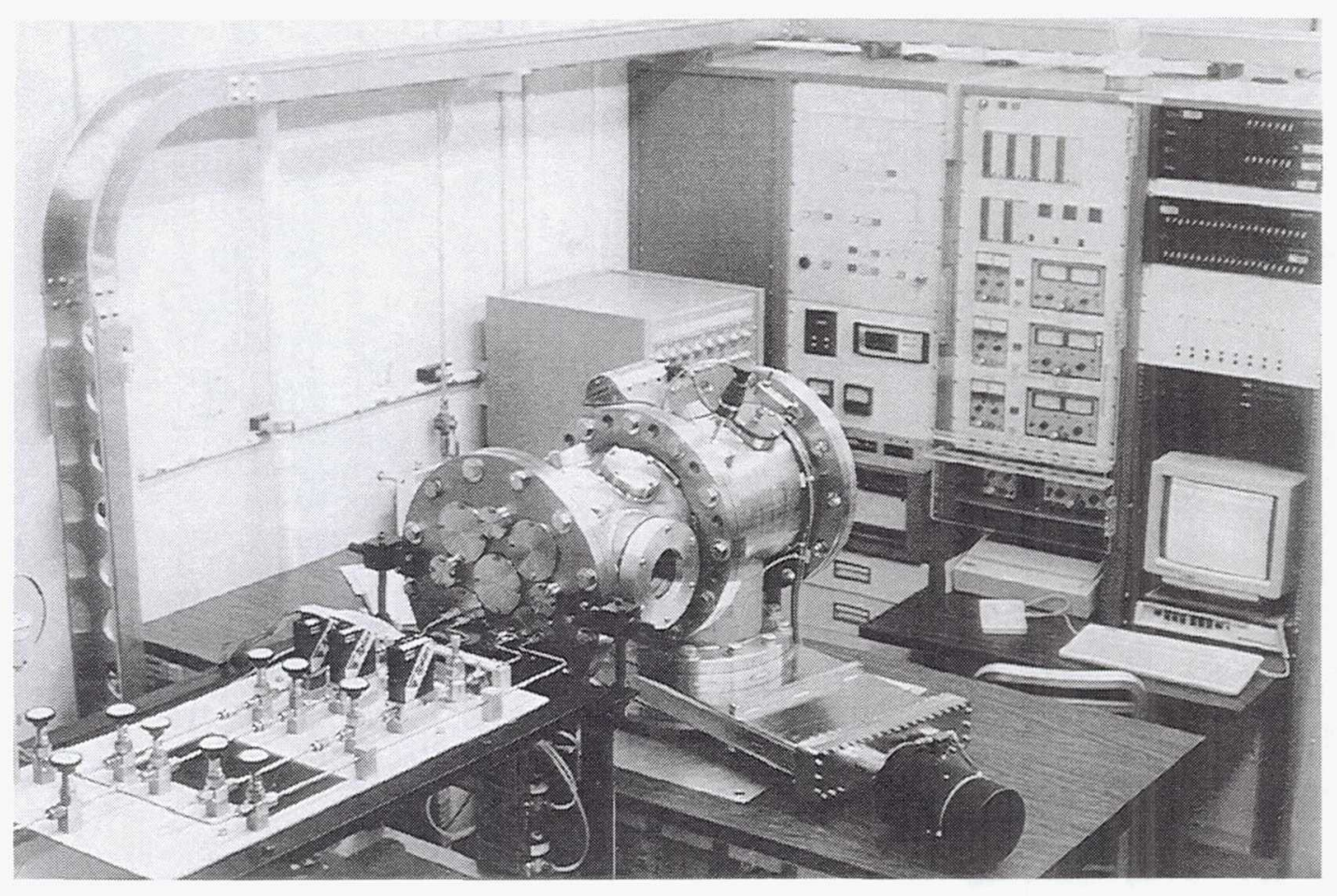

Fig. 5 Ignition testing vacuum facility.

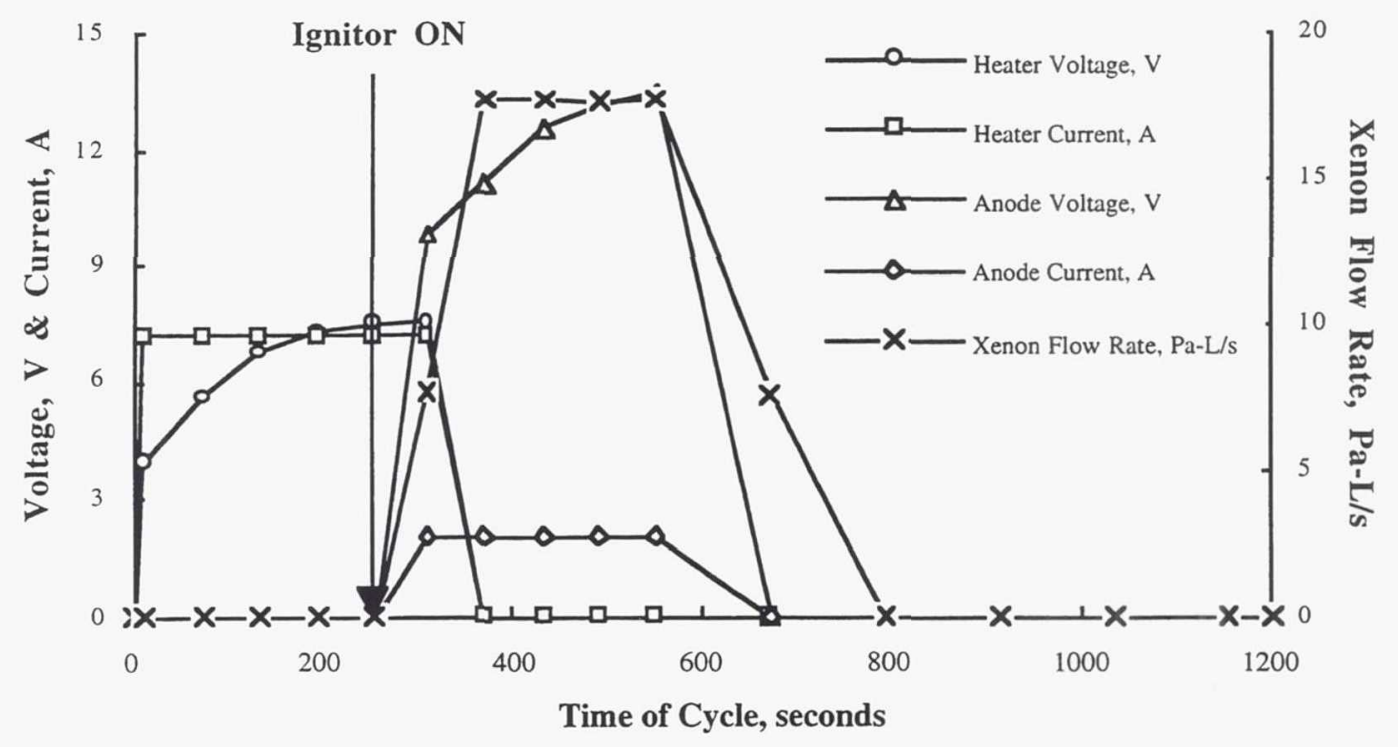

Fig. 6 Ignition cycling test profile. 
(a)

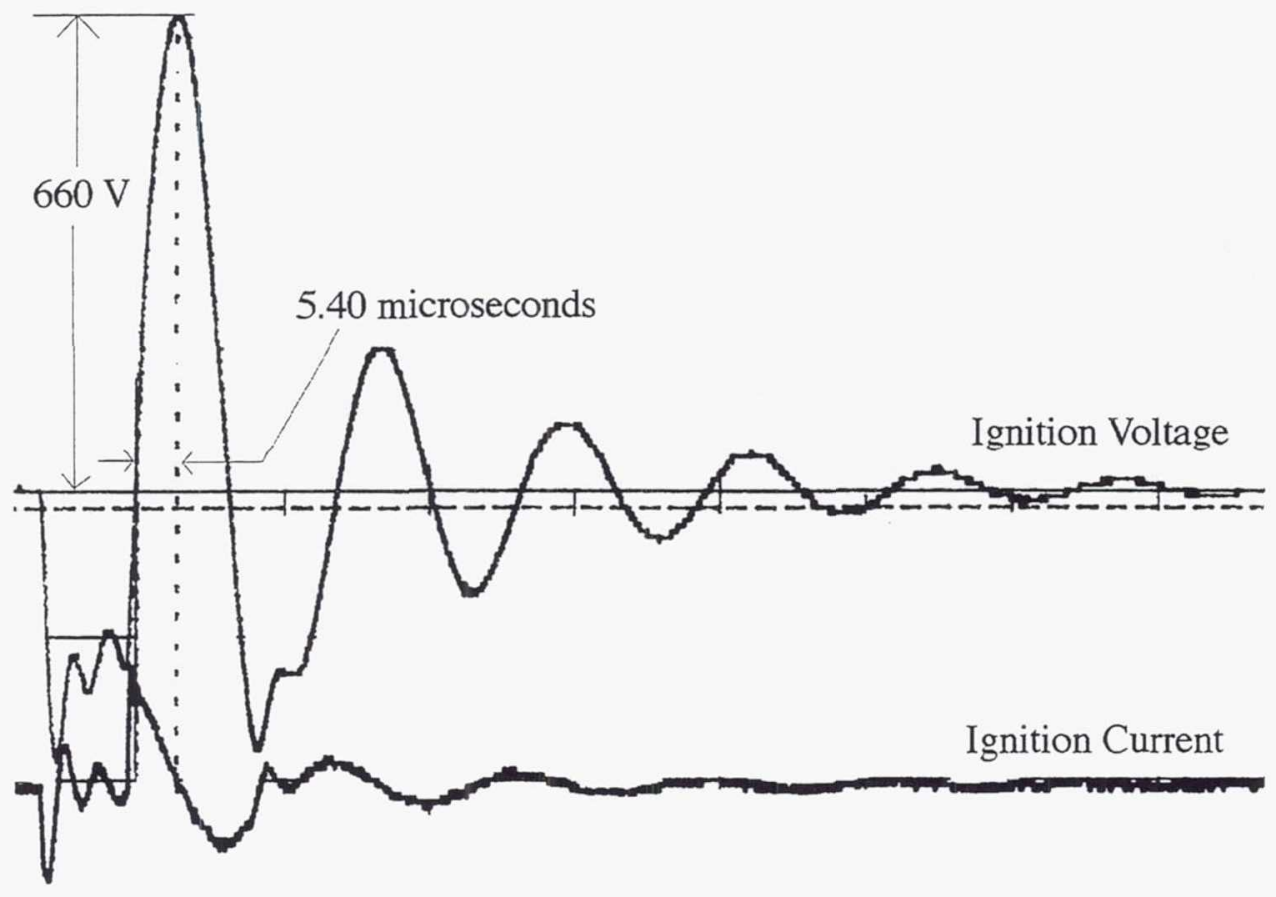

(b)

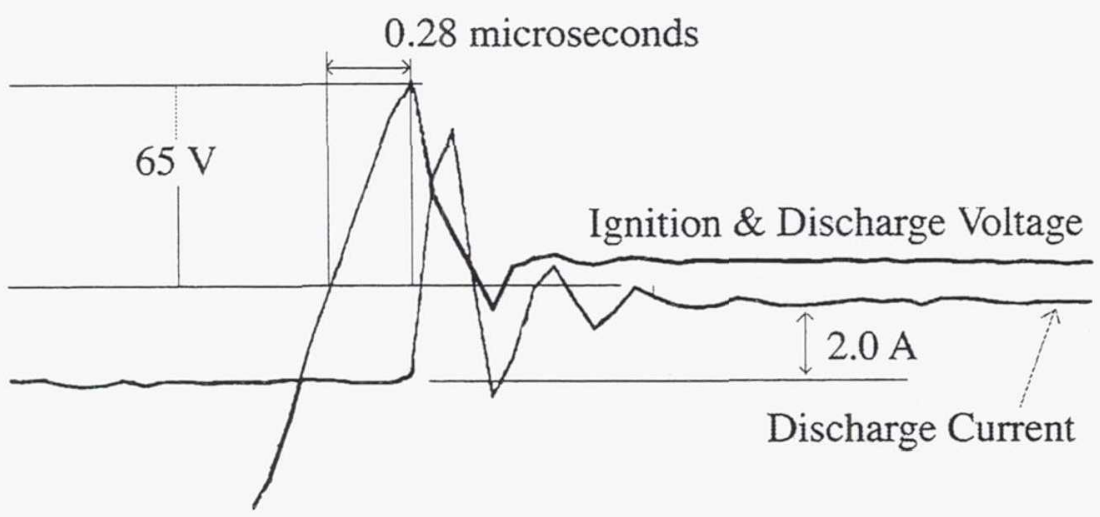

Fig. 7 Ignitor pulse measured at the HCA. (a) is the ignition pulse measured at the initial ignitor with HCA cold and no xenon flow. (b) is the ignition pulse measured with the HCA at pre-heat temperatures and with xenon flowing at the run condition. 


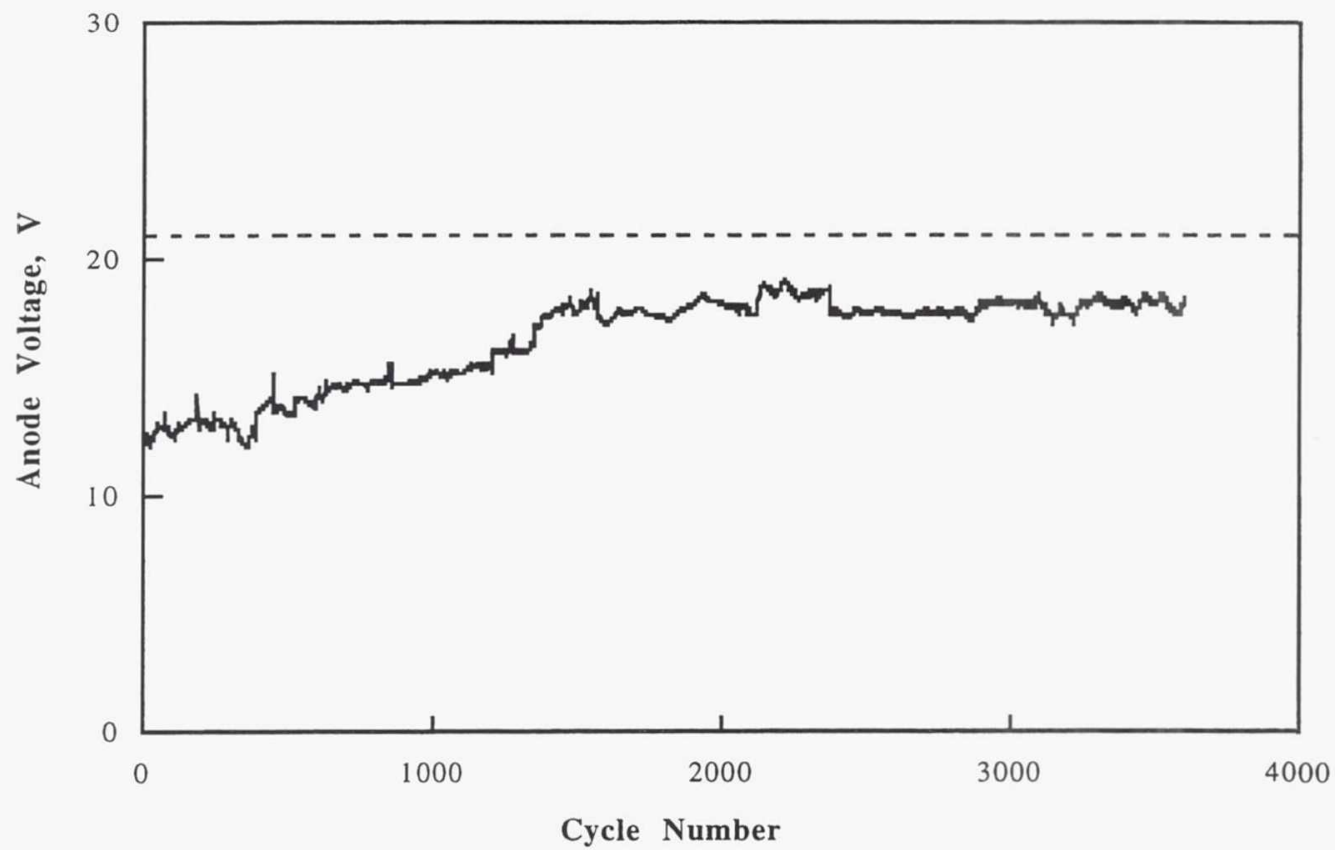

Fig. 8 Anode voltage vs. the number of ignition cycles performed using the prototype HCA. All measurements were taken within the last minute of discharge operation. The discharge current was $2.0 \mathrm{~A}$. The dotted line at $22.0 \mathrm{~V}$ indicates the maximum allowable operating voltage for the HCA. 


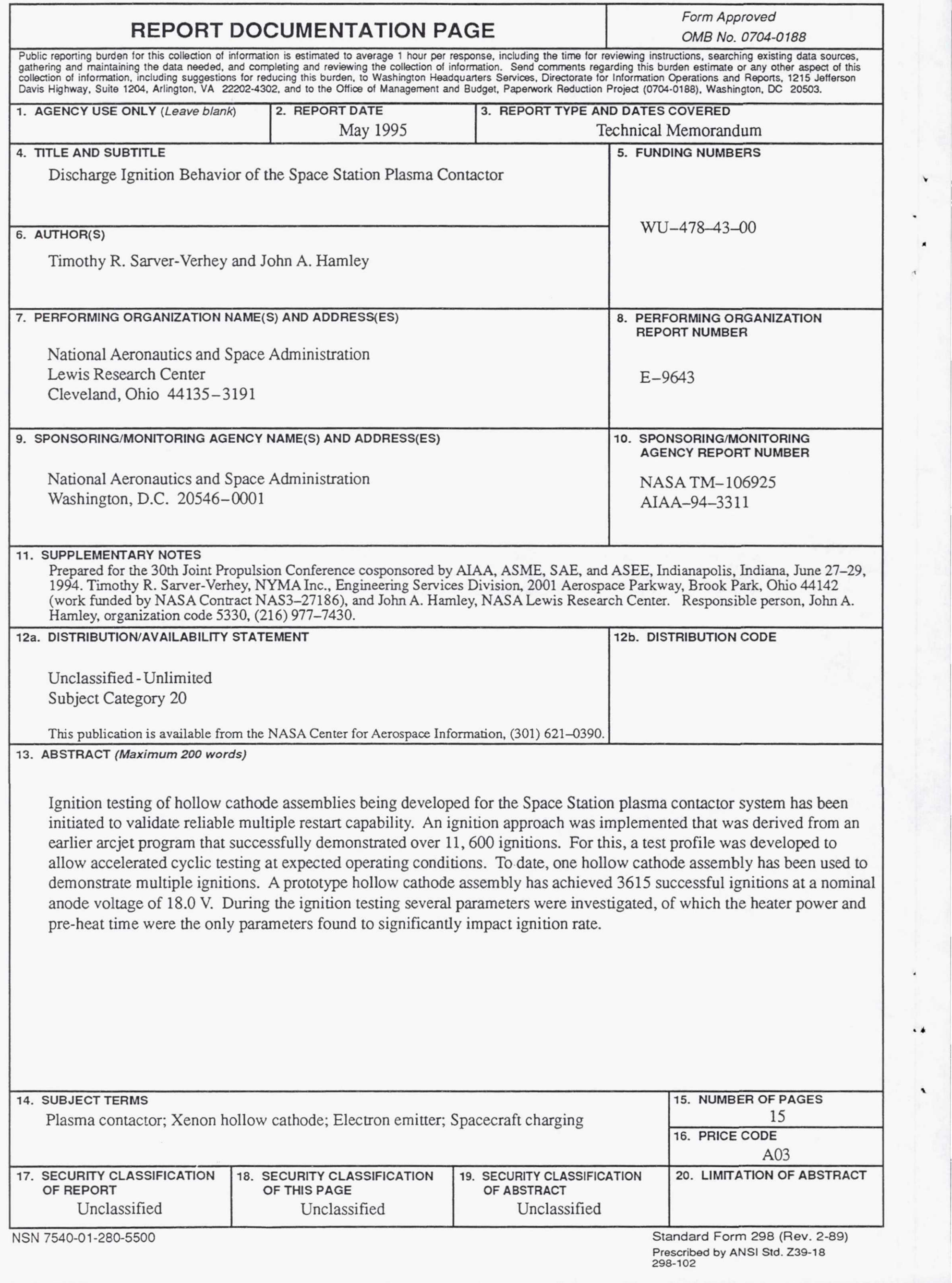

